$\xi^{2}=1$.

\title{
Determining Fracture Pressure Gradients from Well Logs
}

\author{
Udo, K. I'; George, N. J'2; Akankpo, A. O' ${ }^{3}$; Azuoku, G-B ${ }^{4}$; Aka, M. U \\ ${ }^{1}$ Department of Physics, Federal University, Lokoja, Kogi State, Nigeria. \\ ${ }^{2}$ Department of Physics, Akwa Ibom State University, Ikot Akpaden, Akwa Ibom State, Nigeria. \\ ${ }^{3}$ Department of Physics, University of Uyo, Uyo, Akwa Ibom State, Nigeria. \\ ${ }^{4}$ Alex Ekwueme Federal University, Ndufu Alike, Ebonyi State, Nigeria.
}

E-Mail: kufre.udo@fulokoja.edu.ng

\begin{abstract}
Fracture pressure gradient is one of the essential parameters used in determining mud weight profiles during drilling operations. We have determined fracture pressure gradients from well logs obtained from three producing wells in Onshore Niger Delta using an empirical model. Key logs needed for the prediction were conditioned and quality controlled to meet the standard required for reliable results. The true vertical stress, normal compaction trend and compressional shale velocity trends were generated from the logs (density and sonic $\operatorname{logs}$ ). Poison's ratio was obtained from compressional and shear wave velocities derived from sonic log. Pore pressures in the three wells were then predicted using Eaton's Method. The predicted pore pressures, overburden pressures and poison's ratio were used to determine fracture pressures using Ben Eaton's Model. Results showed that there is a suitable drilling margin at all depths only in well G-005. Drilling well A-001 to a depth of $10962.81 \mathrm{ft}$ and K-001 to a depth of $12626.9 \mathrm{ft}$ will fracture the formations because the fluid pressures at those depths approximate the fracture pressures of $8536.7 \mathrm{psi}$ and $9506 \mathrm{psi}$ with corresponding gradients of $0.78 \mathrm{psi} / \mathrm{ft}$ and $0.75 \mathrm{psi} / \mathrm{ft}$ respectively. The implication is that drilling deeper in the field will results in very low seal capacity magnitudes, thereby presenting a higher risk of top-seal failure.
\end{abstract}

Keywords:Fracture gradient; Overburden stress; Pore Pressure; Poison's Ratio.

\section{Introduction}

Fracture pressure is the pore pressure which would cause a reservoir to fracture. It is the pressure required to fracture the formation and cause mud loss from wellbore into the induced fracture. Fracture pressure depends on the minimum horizontal stress and is typically 80 95\% of the lithostatic stress at a given depth (Yardly and Swarbrick, 2000 ). Since fracture gradient is the maximum mud weight, it is an important factor for designing a mud weight while planning for drilling as well as during the actual drilling. If mud weight is equal to or above the formation fracture gradient, there will be tensile failure of the wellbore causing losses of drilling mud or even lost circulation (Zhang, 2011). Fracture pressure can be measured directly from downhole leak-off test (LOT) and can also be predicted from well logs. High formation pressures are always caused by disequilibrium compaction or other fluid expansion mechanisms and may reach a critical value such that if exceeded, may fracture the formation. Overpressure is the pressure which exceeds the pressure of a static column of water or brine (Dickinson, 1983). It is the result of the inability of formation fluid to escape at a rate which maintains equilibrium with a column of formation water that exists to the surface (Swarbrick and Osborne, 1996). Overburden stress or lithostatic pressure is the weight of the entire overburden and it increases with depth. The difference between the lithostatic stress and the pore pressure is the effective stress on the formation.

An accurate prediction of the subsurface pore pressures and fracture gradients is a necessary requirement to safely, economically and efficiently drill the wells required to test and produce oil and natural gas reserves (Udo, et al., 2015). Well control events such as formation fluid kicks, lost circulation, surface blowouts and underground blowouts can be avoided with the use of accurate fracture gradient predictions in the design process (Fooshee, 2000). Drilling in areas of high pressure such as Niger Delta requires a well plan that involves both pore pressure and fracture gradient predictions. Formation pressures are successfully determined by analysis of relevant data, coupled with compaction, stress and temperature histories. Knowledge of rock types, their distributions and subsurface structure and reservoir connectivity are also relevant information required to determine pore and fracture pressures. Fracture gradients are largely dependent on rock properties where lithology, compaction state and degree of lithification are within the context of local and regional stresses. Attempting to predict pore pressure and fracture gradients away from local well control can pose serious challenges. Hence any approach which can reduce unscheduled downtime is more economical, and more accurate predictions will reduce the likelihood of influxes and mud losses which improve safety of the well operations (Swarbrick and Osborne, 1998). 


\section{Location of the study area}

The study area is located in the onshore part of the South-South Niger Delta. The Niger Delta is underlain by three stratigraphic units, the deepest Akata Formation, the middle Agbada Formation and the top Benin Formation. The Benin Formation is mainly made up of continental sand deposits with intercalation of shale and is covered with topmost low velocity layer which in most cases is weathered within which surface waves are excited and generated. Immediately below the Benin Formation is the reservoir sand of the Agbada Formation which is believed to house the oil and gas resource of the Niger Delta. The Akata Formation is also believed to be the source rock for the petroleum resource and hydrocarbon reservoirs in deep offshore.

\section{Methodology}

The procedure began with generating normal compaction trend, overburden stress and shale velocity (Vp) trend as inputs for pore pressure prediction. Pore pressure was then predicted using the Modified Eaton's method with an exponent of 5.

The Eaton's equation used in calculating pore pressure is given by

$$
P_{p}=S_{v}-\left(S_{v}-P_{n}\right)\left(\frac{V p_{\text {obs }}}{V_{\text {pnorm }}}\right)^{5}
$$

Where $P_{p}$ is the pore pressure; $S_{v}$ is the total vertical stress (overburden or lithostatic pressure); $P_{n}$ is the normal or hydrostatic pressure; $\mathrm{Vp}$ is the observed sonic velocity at any depth; $\mathrm{Vp}$ norm is sonic velocity when pore pressure is normal.

The poison ratio, $\gamma$ was obtained using equation 2 below

$$
\gamma=\frac{\frac{1}{2}\left(\mathrm{v}_{\mathrm{p}} / \mathrm{v}_{\mathrm{s}}\right)^{2}-1}{\left(\mathrm{v}_{\mathrm{p}} / \mathrm{v}_{\mathrm{s}}\right)^{2}-1}
$$

Where $\mathrm{v}_{\mathrm{p}}$ and $\mathrm{v}_{\mathrm{s}}$ are compressional and shear wave velocities from sonic log.

Finally, Fracture pressures at different depths were predicted using the predicted pore pressures and calculated poison ratios. Fracture gradient estimation methods include Hubbert and Willis, Mattew and Kelly, and Ben Eaton. We used Eaton's method to predict the fracture pressure gradient. The equation used is as follows :

$$
\mathrm{FG}=\frac{\gamma}{1-\gamma}\left(\frac{\mathrm{S}_{\mathrm{v}}-\mathrm{P}_{\mathrm{p}}}{\mathrm{Z}}\right)+\frac{\mathrm{P}_{\mathrm{p}}}{\mathrm{Z}}
$$

Where FG is the fracture pressure gradient in psi/ft, $\mathrm{S}_{\mathrm{v}}$ is Overburden stress in psi, Pp is pore pressure in psi, $\mathrm{Z}$ is depth in $\mathrm{ft}, \mathrm{Pp} / \mathrm{Z}$ is $\mathrm{Pore}$ pressure gradient in $\mathrm{psi} / \mathrm{ft}$. and $\gamma$ is Poisson's ratio.

The advantage of the Eaton's Model is that it takes into consideration the effect of different rock types (shale and sand stone) on fracture gradient since the lithology effect is considered in poison ratio calculated from equation 2 . The logs and other drilling data were used to generate the overburden and calibrate the wells. The normal compaction trends and other parameters used in calculating pore pressure and fracture pressure gradients were also generated. Prediction points (depths and corresponding shale velocities and other properties) were picked (at areas identified from the log suites as shale zones). Equations 1 and 3 were used to carry out the pore pressure and fracture pressure calculations respectively. These values were then used for the pressure versus depth plots from which the fracture gradients were then estimated.

\section{Results}

The NCT, and Vp shale were generated from the logs. The parameters required for the fracture pressure prediction were calculated and

\begin{tabular}{|c|c|c|c|c|c|}
\hline Depth (TVDss) & OBP & Phyro & PPP & Poisson Ratio & Fracture Pressure \\
\hline 7867.42 & 8593.649 & 3555.039 & 3190.084 & 0.422284 & 5718.109 \\
\hline 7895.91 & 8624.716 & 3567.86 & 4630.052 & 0.422456 & 5790.982 \\
\hline 7919.48 & 8650.418 & 3578.466 & 4733.241 & 0.422598 & 5862.717 \\
\hline 7951.31 & 8685.126 & 3592.79 & 4838.422 & 0.422788 & 5950.703 \\
\hline 8243.82 & 9042.507 & 3724.419 & 4965.144 & 0.424493 & 6211.397 \\
\hline 8524.04 & 9428.82 & 3850.518 & 5184.214 & 0.426058 & 6466.038 \\
\hline 8770.63 & 9742.03 & 3961.484 & 5401.758 & 0.427382 & 6790.643 \\
\hline 9895.16 & 11173.67 & 4467.522 & 5766.514 & 0.432864 & 7650.47 \\
\hline 10056.88 & 11402.91 & 4540.296 & 6378.575 & 0.433585 & 7773.257 \\
\hline 10725.75 & 12310.27 & 4841.288 & 6457.437 & 0.43641 & 8349.047 \\
\hline 10884.62 & 12492.39 & 4912.779 & 6918.413 & 0.437046 & 8556.498 \\
\hline
\end{tabular}
tabulated in Tables $1-3$.

Table 1: Calculated Fracture Pressures of Well A-00 


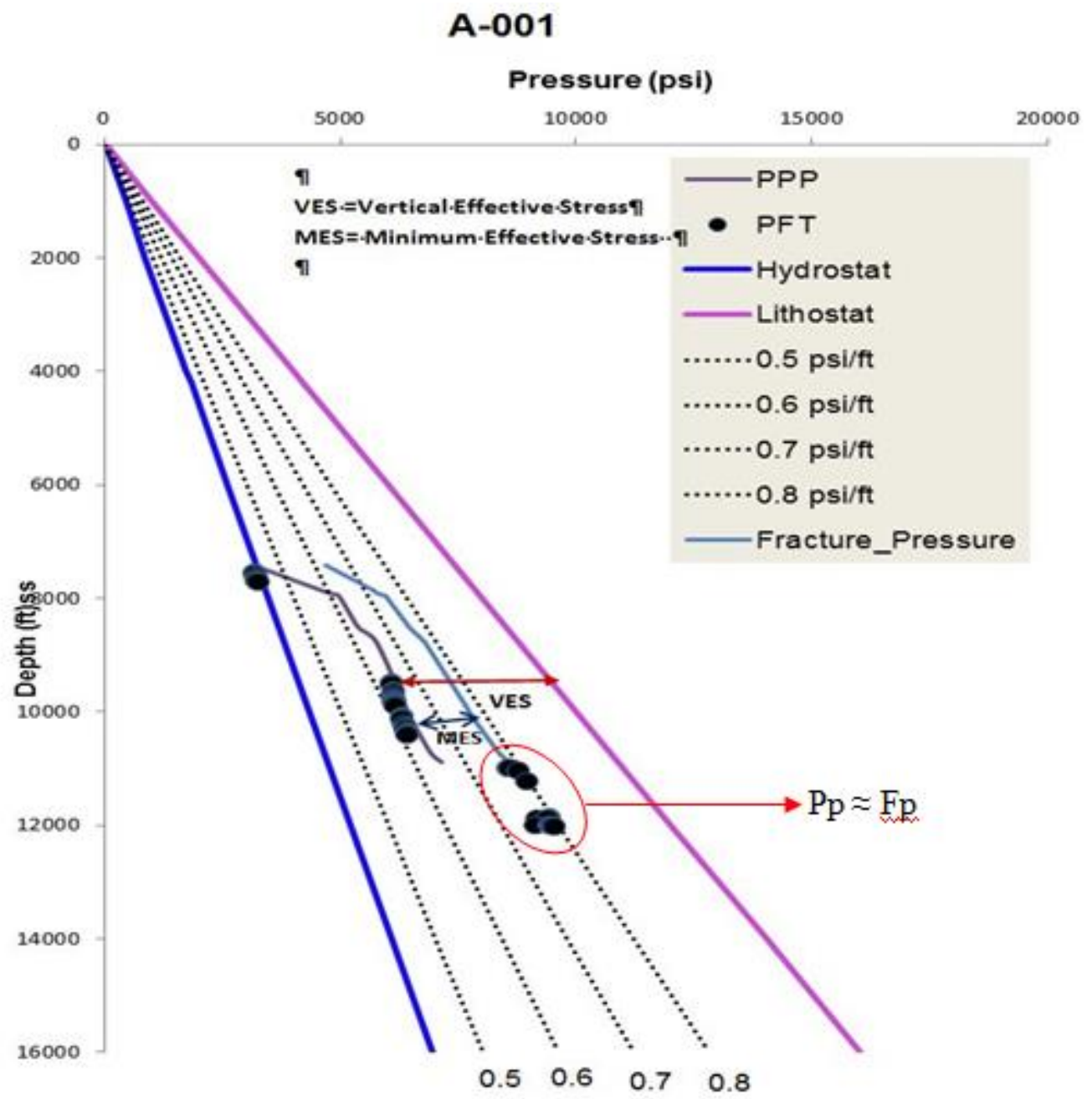

Fig. 1:P-Z Plot Showing Fracture Pressure of Well A-001.

Table 2:Calculated Fracture Pressures of Well G-005

\begin{tabular}{|c|c|c|c|c|c|}
\hline 3 & OBP & Phydro & PPP & Poisson Ratio & Fracture Pressure \\
\hline 9163.46 & 9494.483 & 4138.257 & 3974.793 & 0.429396 & 5644.493 \\
\hline 9376.38 & 9758.447 & 4234.071 & 4219.578 & 0.430441 & 5877.923 \\
\hline 9599.69 & 10035.24 & 4334.561 & 4125.068 & 0.431505 & 5921.853 \\
\hline 10328.25 & 10988.26 & 4662.413 & 4670.472 & 0.434761 & 6550.365 \\
\hline 11179.15 & 12100.7 & 5045.318 & 4901.959 & 0.438192 & 7065.616 \\
\hline 12381.62 & 13746.91 & 5586.429 & 5453.211 & 0.442468 & 7933.947 \\
\hline 12508.86 & 13946.32 & 5643.687 & 5767.723 & 0.442886 & 8169.927 \\
\hline 13843.43 & 15884.25 & 6244.244 & 6248.515 & 0.446931 & 9081.292 \\
\hline 14298.49 & 16539.18 & 6449.021 & 6521.223 & 0.448182 & 9459.363 \\
\hline 14412.6 & 16738.22 & 6500.37 & 6925.428 & 0.448487 & 9738.55 \\
\hline 15438.74 & 18288.61 & 6962.133 & 10036.95 & 0.451073 & 11972.26 \\
\hline 15597.9 & 18549.68 & 7033.755 & 10492.87 & 0.451451 & 12305.19 \\
\hline
\end{tabular}




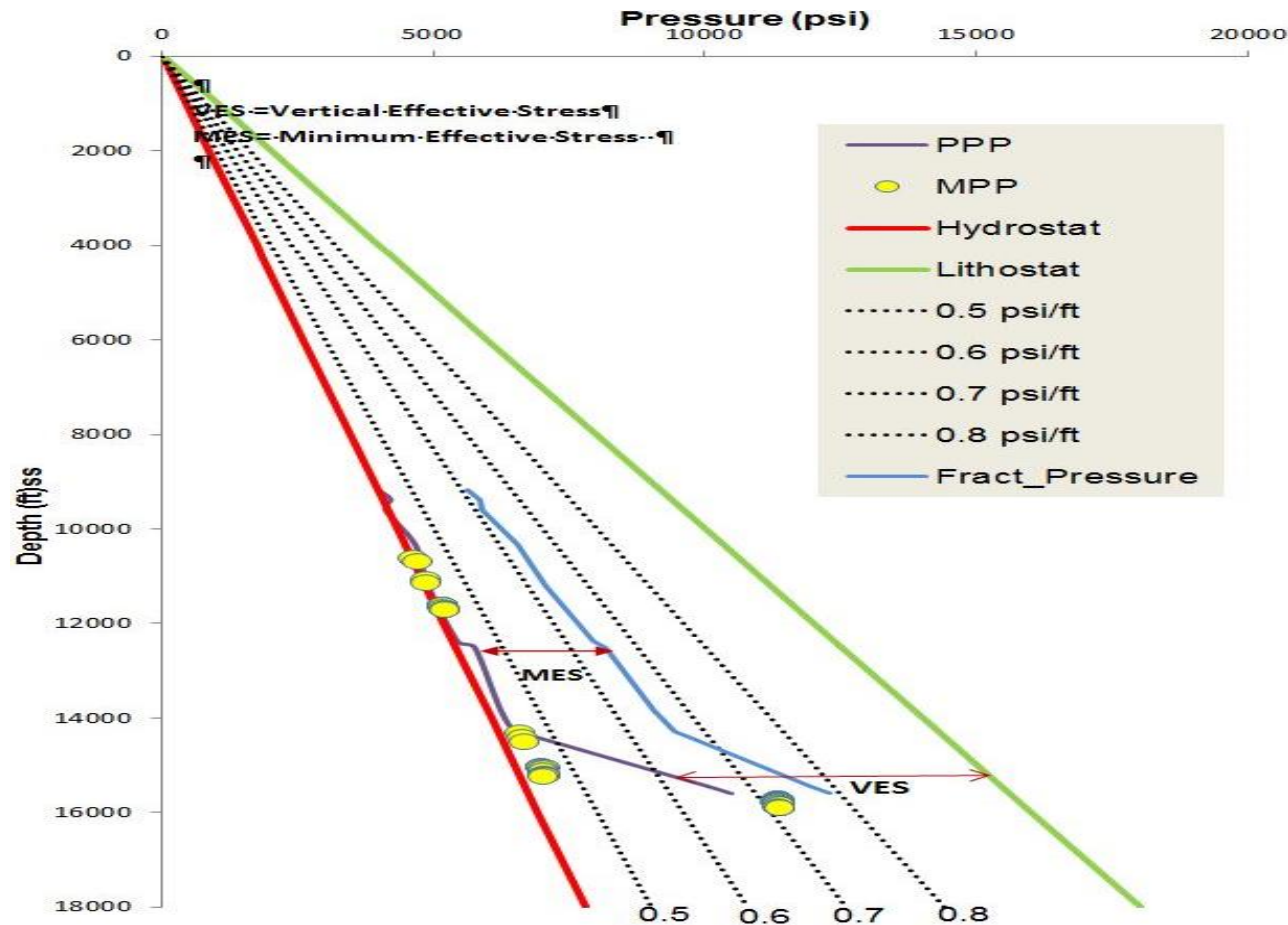

Fig. 2:P-Z Plot Showing Fracture Pressure of Well G-005.

Table 3: Calculated Pore Pressures and Fracture Pressure for Well K-001

\begin{tabular}{lllll}
\multicolumn{3}{c}{ Table 3: Calculated Pore Pressures and Fracture Pressure for Well K-001 } \\
\hline Depth (TVDss) & OBP & Phydro & PPP & Poisson Ratio \\
\hline 9513.12 & 8583.57 & 4295.604 & 4816.753858 & 0.431096828 \\
9571.27 & 8590.31 & 4321.772 & 4819.996604 & 0.431371802 \\
9626.11 & 8699.99 & 4346.45 & 4409.060498 & 0.431629121 \\
9723.41 & 8802.87 & 4390.235 & 4656.30224 & 6.432080951 \\
9864.64 & 8951.56 & 4453.788 & 5273.182104 & 0.432726255 \\
10125.12 & 9222.02 & 4571.004 & 5562.685335 & 0.433884822 \\
11107.37 & 10252.41 & 5013.017 & 6037.438598 & 0.437916618 \\
11192.09 & 10343.79 & 5051.141 & 6745.447696 & 0.43824145 \\
11753.94 & 10927.23 & 5303.973 & 7056.083987 & 0.440312547 \\
10677.44 & 9800.23 & 4819.548 & 5080.539444 & 0.436214076 \\
10093.74 & 9188.47 & 4556.883 & 5357.276841 & 703488 \\
9083.14 & 8146.75 & 4102.113 & 4221.722601 & 0.433747368 \\
\hline
\end{tabular}

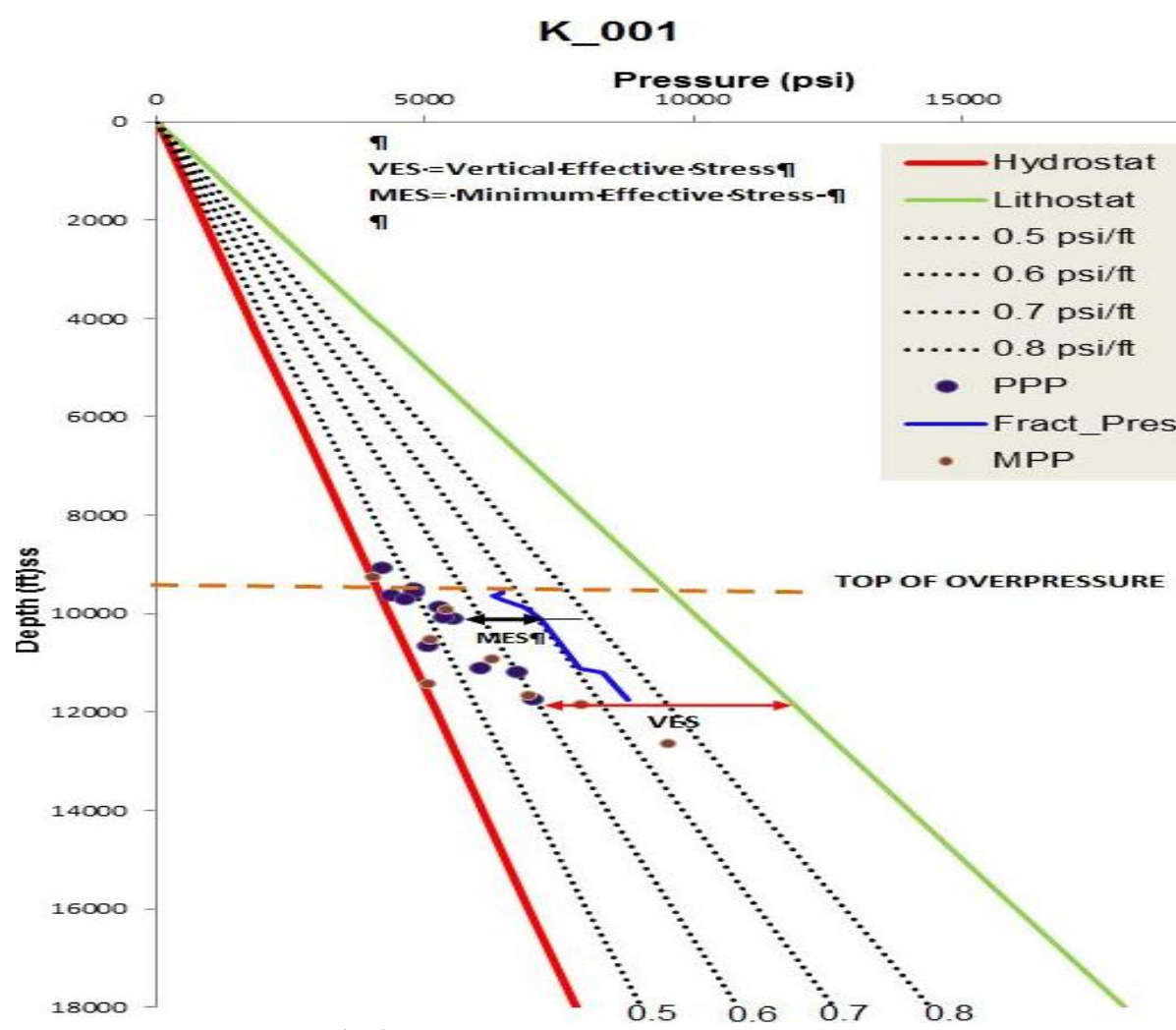

Fig. 3:P-Z Plot Showing Fracture Pressure of Well K-001. 


\section{Discussion}

The results obtained showed that the shale at all the well locations possess suitable drilling margins only to certain depths. Drilling margin or drilling window according to Gaarenstroom et al (1993), is the difference between the formation pressure and the fracture pressure in a formation. By this definition, results of this work showed that the shale in A-001 and K-001 may suffer hydraulic failure if drilled at depths of $1092.81 \mathrm{ft}$ and $1262.9 \mathrm{ft}$ respectively. Hydrocarbon accumulations trapped beneath a seal can be lost through a membrane leakage or hydraulic failure. This occurs when the hydrocarbon buoyancy pressure is higher than the seal's capillary entry pressures.

In well A-001 (figure 1), the rock would be fractured if drilled to depth of $10962.81 \mathrm{ft}$. The formation pressure at this depth is equal to the fracture pressure making the minimum effective stress to become zero. The implication is that the mud weight required to balance the formation pressure at that depth will fracture the formation and then leads to hydrocarbon leakage.Well G-005 (figure 2) can be drilled up to $16000 \mathrm{ft}$ and beyond without fracturing the rock because the pore pressures do not approximate the fracture pressure at any depth. Drilling well K-001 to a depth of 12626.9ft and beyond will lead to fracturing (figure 3). The fluid pressure of $9506 \mathrm{psi}$ at this depth is very close to the fracture pressure leading to a near zero minimum effective stress. While drilling these wells with drilling fluid, after overcoming the mud cake, if the mud weight is transmitted to the rock and it exceeds minimum principal stress and minimum fracture pressure, the formation will fracture and cracks will extend along a direction normal to the minimum principal stress of the formation, resulting in circulation loss. Fluid pressures which are close to the fracture gradient tend to occur where a secondary overpressure mechanism operates.

\section{Conclusion}

We have shown that fracture pressure gradients can be determined using well logs instead of direct measurements which are only be possible at permeable beds. We have also assessed the strength of the shale seal at the locations. The depths and the corresponding pressures at which the reservoir would fracture if drilled have been identified in all the wells. This was achieved using the predicted fluid pressures, the generated overburden pressures and poison ratio derived from the compressional and shear wave velocities. Finally, the result of this work has shown that drilling deeper in the studied field will result in seal capacity magnitudes of only a few 100 's, thereby increasing the risk of top-seal failure.

\section{Acknowledgement}

We acknowledge Shell Petroleum Development Company of Nigeria for the data used in this work.

\section{References}

[1] Dickinson G., (1983). Geological aspects of abnormal reservoir pressures in Golf Coast Louisiana" Bull Am assoc. Pet. Geol., v 37.410 - 432.

[2] Eaton, B.A., (1972). The effects of Overburden Stress on Geopressure Prediction from well logs: Journal of Petroleum Technology, v. 24, 929 934. https://doi.org/10.2118/3719-PA.

[3] Fooshee, J. S. (2000). The development of a pore pressure and fracture gradient prediction models for the Ewing Banks 910 area in the Golf of Mexico. Published M.sc thesis, M.sc in Petroleum Engineering, Louisiana University.

[4] Gaarenstroom, L., Tromp, R. A. J., Jong, de. M. C. and Brandenburg. A. M. (1993). Overpressures in the Central North Sea: implications for trap integrity and drilling safety. In: Parker, J. R. (Editors) Petroleum Geology of the NorthwestEurope: Proceedings of the 4th Conference. Geological Society, London, 1305-1313.https://doi.org/10.1144/0041305.

[5] Jeffrey S. Fooshee, (2009). The development of a pore pressure and fracture gradient prediction models for the Ewing Banks 910 area in the Golf of Mexico. Published M.sc thesis, M.sc in Petroleum Engineering, Louisiana University.

[6] Jiao J.J. and Zheng M. V. (1998), Abnormal fluid pressures caused by deposition and erosion of sedimentary basins. Journal of Hydrology, 13, pp124 - 141.https://doi.org/10.1016/S0022-1694(97)00115-7.

[7] Swarbrick R.E. and Osborne M.J (1996). The nature and diversity of pressure transition zones: Petroleum Geoscience, v.2, p.111116.https://doi.org/10.1144/petgeo.2.2.111.

[8] Swarbrick R.E. and Osborne M.J. (1998), Mechanisms that generate abnormal pressures. An Overview, in B.E. Law, G.F Ulmishek, and V.I slavin, eds, Abnormal pressures in hydrocarbon environments: AAPG memoir, v 70, 13- 34.

[9] Udo, K.I, Akpan, M.J and Agbasi,O. E.(2015). Estimation of Overpressures in Onshore Niger Delta Using Wire-line Data.International Journal of Science and Research, 4(5): 2780-2784.

[10] Yardly, G.S and R.E Swarbrick (2000), Lateral Transfer: a source of additional overpressure: Marine and Petroleum Geology, v.17, p.523 538.https://doi.org/10.1016/S0264-8172(00)00007-6.

[11] Zhang, J. (2011). Pore pressure prediction from well logs: Methods, modifications, and new approaches. Earth Science Reviews 108: 5063.https://doi.org/10.1016/j.earscirev.2011.06.001. 